\title{
Nonlinear Finite Element Analysis of New Precast Concrete Shear Wall
}

\author{
TANG Lei \\ College of Civil Engineering, Southeast University, Nanjing 210096, China \\ zzfking2210@163.com
}

Keywords: precast concrete, shear walls, nonlinear analysis, experiment.

Abstract. New precast concrete shear walls use mild steel bars protruded from lower precast concrete wall and anchored in grouted metal bellows embedded in upper precast concrete wall to form integrity. The horizontal connection of precast shear walls is frequently located a certain distance higher than the story floor. Thus the force mechanism of new precast shear wall is probably different from that of traditional monolithic wall. Based on the completed seismic experiments on new precast concrete shear wall, nonlinear finite element model was established to simulate the lateral performance of the tested precast specimen. The nonlinear finite element model was evaluated by comparing the calculated lateral force versus lateral displacement curve with the measured skeleton curve. The comparison results showed that the established nonlinear finite element model had good consistence with the tested specimen.

\section{Introduction}

New precast concrete shear walls consist of precast shear wall prefabricated in accordance with structural story height. The mild steel reinforcing bars were placed across the horizontal connections between precast wall panels. The reinforcing bars corresponding to the vertical reinforcements of the precast wall panel were protruded from the top of precast wall panel (lower precast wall panel) and anchored in metal bellows embedded in the bottom of precast wall panel (upper precast wall panel) and filled with high-strength grout. The position of the horizontal connection is intentionally offset to a certain distance (frequently $600 \mathrm{~mm}$ ) from the floor level to insure structural safety and construction convenient. [1]

Precast concrete shear walls are main structural component providing lateral resistance under earthquake loading. Khaled A. Soudki, etc. [2,3] carried out serial experiments on typical connections of precast concrete shear walls. The test results showed that precast concrete shear walls were capable of providing integrity by grouted reinforcing bars placed across the horizontal connection.

With regard to new precast concrete shear wall, as shown in Fig. 1, accomplished related experiments [1] had shown that the force mechanism and failure mode of the tested specimens were significantly different from that of the reference monolithic cast-in-place specimen. In this paper, nonlinear finite element analysis was conducted to achieve the lateral performance of new precast concrete shear walls.

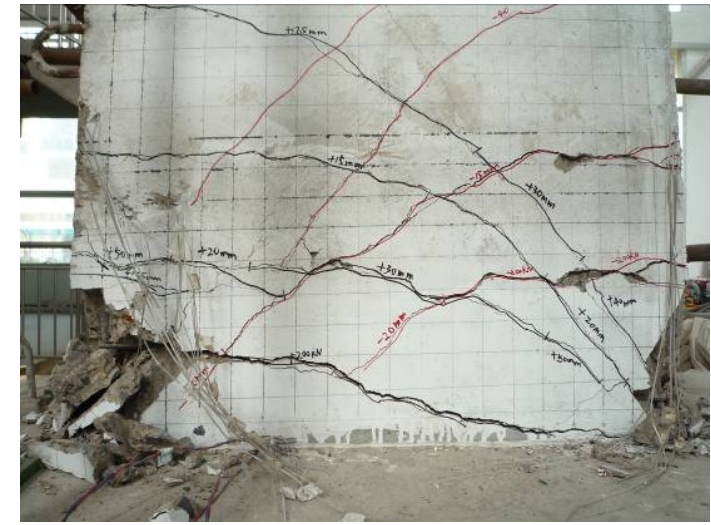

(a) monolithic specimen

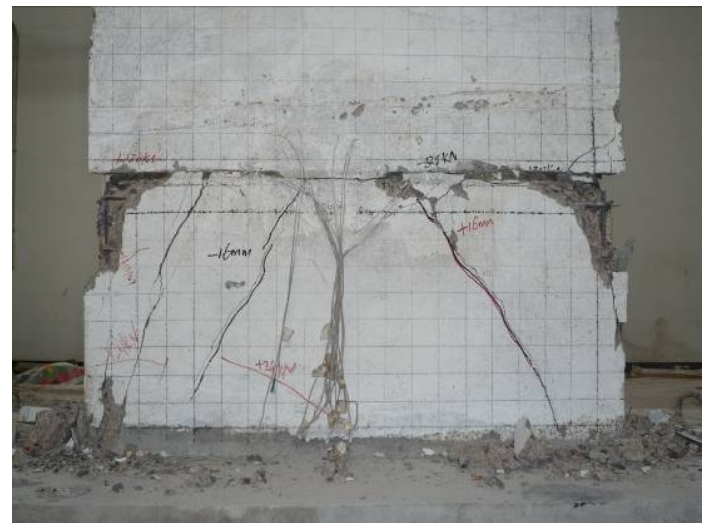

(b) precast specimen

Fig. 1 Failure modes of tested specimens 


\section{Prototype Specimen}

The experiment involved two identical specimens. The details of tested specimen are shown in Fig. 2. The specimen consisted of two components including base and shear wall in which the base representing the structural foundation, the wall simulating the bottom-storey shear wall in the structure. Plain concrete of strength grade C30 (the standard value of cubic compressive strength is $30 \mathrm{MPa}$ ) was used to form the specimen. The reinforcements used mild steel of grade HRB400 (the design value of yielding strength is $360 \mathrm{MPa}$ ). The grout filled in the embedded metal bellows of diameter $50 \mathrm{~mm}$ had the compressive strength of 50MPa. Grouted reinforcing bars were set at both toes of the wall panel. The Z-type horizontal connection configuration was employed to achieve building waterproof function. $15 \mathrm{~mm}$ thick grout pad was set as leveling course and it made sure that the precast concrete at the horizontal connection intersection surface under equal compressive stress.
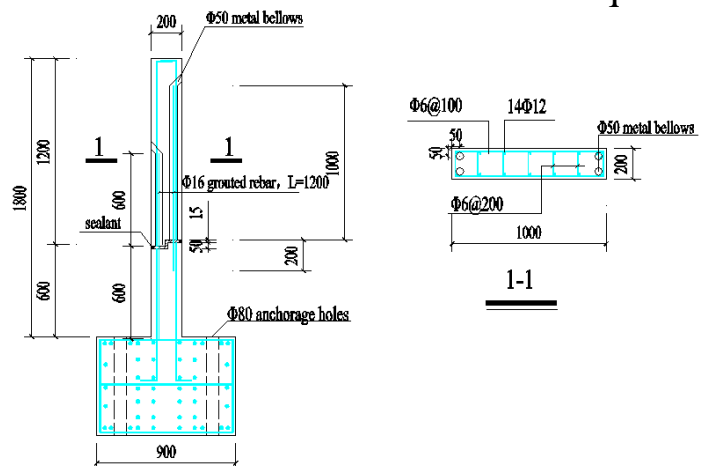

Fig. 2 Details of tested precast specimen

The measured compressive strengths of concrete and grout were $38 \mathrm{MPa}$ and $60 \mathrm{MPa}$, respectively. The measured yielding strength and ultimate strength for mild steel bars were $492 \mathrm{MPa}$ and $656 \mathrm{MPa}$, respectively.

Low cyclic reverse lateral loading was applied on the specimen at the distance of $1700 \mathrm{~mm}$ from the top of the base. The lateral load was applied first based on force control with one cycle at each increment until yielding, and afterword, it was loaded by displacement control as a multiple of yield displacement with three cycles at each increment.

\section{Finite Element Modeling}

Finite element software ANSYS [4,5,6] was employed to simulate the tested specimen. SOLID65 element was used to emulate the concrete behavior and LINK8 element was used to emulate the steel behavior. Multi-linear isotropic strengthening model and Willam-Warnker failure criterion were applied in concrete constitutive model. Bi-linear kinetic strengthening model was applied in the steel constitutive model. Surface-to-surface contact pair composed of targe170 and conta174 elements were used to simulate the open/close behavior of the horizontal connection. In order to reduce the calculation time and ensure result accuracy, several assumptions or simplifications were introduced in the modeling progress:

(1) The crush behavior of concrete was neglected to avoid convergence difficulties, and

(2) The material strengthening after yielding of the mild steel was not considered to indirectly simulate the Bauschinger effect, and

(3) The base of the tested specimen was excluded from the model to reduce analysis cost, and

(4) The bond-slip relationship between mild steel bars and surrounding concrete was neglected to reduce the complexity of the finite element model and simultaneously did not affect the calculation accuracy, and

(5) The Z-type architectural configuration was replaced as straight surface, and

(6) The grout pad was excluded from the model to reduce the complexity, and

(7) The local concrete was intentionally strengthened by increasing the elastic modulus to eliminate the influence to the analysis by stress concentration. 
The nonlinear finite element model are shown in Fig. 3. All the nodes at the bottom surface of the wall were pinned to simulate the function of base of the specimen. The vertical load was replaced by the pressure at the top surface of the wall. The out-of-plane deformation was restricted in this model. The monotonic lateral load was applied on the model replacing the reverse loading in the experiment.

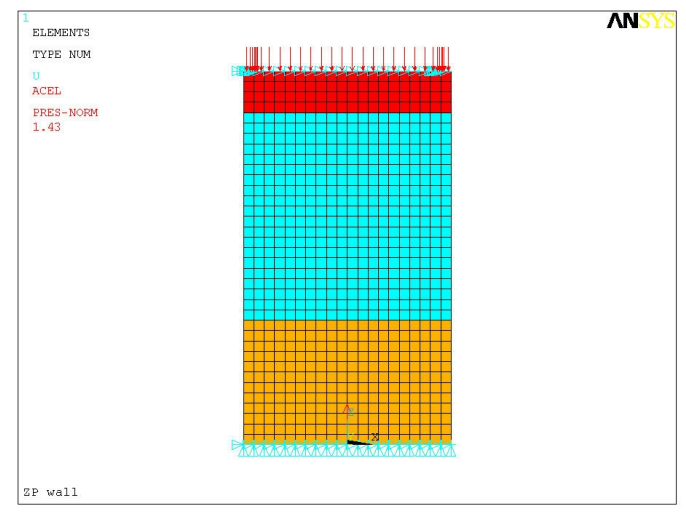

Fig. 3 Nonlinear finite element model

\section{Model Validation}

The nonlinear finite element model was verified through the comparison between calculated lateral-force-to-lateral-displacement curve and the measured skeleton curves of the tested specimens. The comparison result is shown in Fig. 4. The calculated curve was approximately identical to that of the tested specimens. The nonlinear finite element model well predicted the strength of the specimen with the error limited to $12 \%$. However, due to the boundedness of the finite element method, it had relatively large difference between calculated and measured curves.

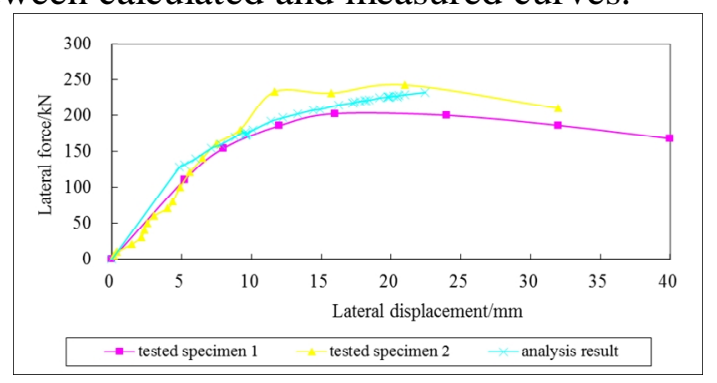

Fig. 4 Comparison of the curves

Besides, the final failure condition of the nonlinear finite element model is illustrated in Fig. 5. The shear failure of the lower panel could be obvious observed, which was equivalent to that shown in Fig. $1(b)$.

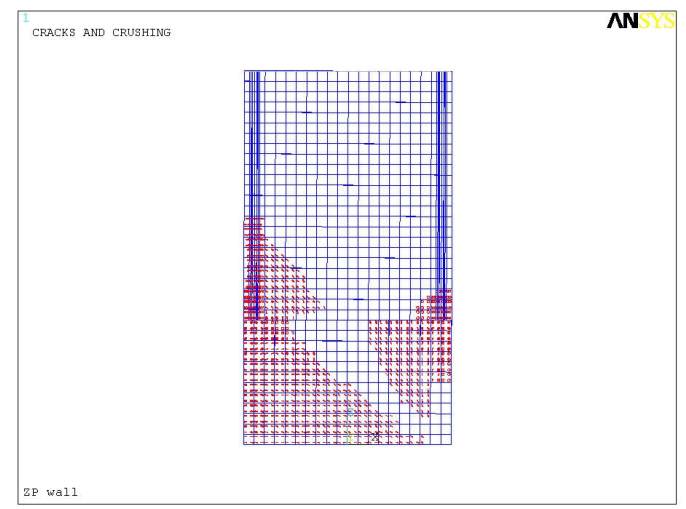

Fig. 5 Failure mode of the model 


\section{Summary}

New precast concrete shear wall behaves differently as compared with monolithic cast-in-place concrete shear wall mainly due to the presence of the horizontal connection and the position of connection offset from the floor level. Nonlinear finite element model was established and the accuracy of the model was verified by accomplished experiment. The nonlinear finite element model was capable of representing the lateral performance of the tested specimen and could be regarded as reference model for further parametric analysis and researching the lateral force mechanism of new precast concrete shear wall.

\section{References}

[1] ZHU Zhang-feng, GUO Zheng-xing. LOW-CYCLIC REVERSED LOAD TEST ON NEW PRECAST CONCRETE SHORT-LEG SHEAR WALL [J]. ENGINEERING MECHANICS, 2013, 30(5): 125-130.

[2] Khaled A. Soudki, Sami H. Rizkalla, Bill LeBlanc. Horizontal Connections for Precast Concrete Shear Walls Subjected to Cyclic Deformations Part 1: Mild Steel Connections. PCI Journal, 1995, V. 40, No. 4 (July-August): pp. 78-96.

[3] Khaled A. Soudki, Jeffrey S. West, Sami H. Rizkalla, Bruce Blackett. Horizontal Connections for Precast Concrete Shear Wall Panels under Cyclic Shear Loading. PCI Journal, 1996, V. 41, No. 3 (May-June): pp. 64-81.

[4] ANSYS15.0 Contact Technology Guide, ANSYS Inc., November, 2014.

[5] ANSYS15.0 Element Reference, ANSYS Inc., November, 2014.

[6] ANSYS15.0 Structure Analysis Guide, ANSYS Inc., November, 2014. 